\title{
Simulation of Sulphate Reduction by SRB in AMD Systems using AQUASIM
}

\author{
Enoch A. Akinpelu, Elvis Fosso-Kankeu, Frans Waanders and Seteno K. Ntwampe
}

\begin{abstract}
This study presents the modelling of biological sulphate reduction in a heavy-metal laden acid mine drainage with high strength sulphate concentration. A simple dynamic model was utilised for the simulation of the biological sulphate reduction process in a continuously stirred tank reactor. The model developed described substrate utilisation via parameter estimation albeit, low description of biomass formed was obtained. The absolute relative sensitivity analysis of the parameters showed that the maximum specific growth rate of the biomass and the saturation constant were significant.
\end{abstract}

Keywords - Acid mine drainage; Aquasim; substrate utilisation, simulation; sulphate reducing bacteria

\section{INTRODUCTION}

The process of sulphide mineralisation can lead to voluminous of tailings especially in developing nations where mining plays a major role in the economy. The process generates heavy metal-laden acid mine drainage (AMD) with high sulphate concentration due to the weathering and biological oxidation of sulphide containing tailings, including mine waste [1-8]. Traditionally, AMD treatment involves the addition of lime to raise $\mathrm{pH}$ and subsequently precipitate associated heavy metal hydroxides [9]. The other methods for treating AMD includes, chemical precipitation, membrane-filtration, floatation, ion-exchange, reverse osmosis, electrochemical and coagulation-floatation, amongst others [1, 10, 11]. However, these methods are expensive and often require a post-treatment facility for the brine generated. Biological sulphate removal is a cost effective alternative for high strength sulphate containing wastewater such as AMD.

Biological sulphate reduction is performed by diverse groups of sulphate reducing bacteria (SRB) that use sulphate as a terminal electron acceptor. There are reports on the successful application of SRB in high strength sulphate industrial

Manuscript received August 23, 2019. This work is based on the research supported wholly by the National Research Foundation of South Africa (Grant Number: 111993). Any opinion, findings and conclusions or recommendations expressed are those of the authors, and NRF accepts no liability whatsoever in this regard.

E. A. Akinpelu, E. Fosso-Kankeu and F. Waanders are with the Water Pollution Monitoring and Remediation Initiatives Research Group and the School of Chemical and Minerals Engineering, North-West University, Potchefstroom campus, South Africa.

S. K. Ntwampe is with the Bioresource Engineering Research Group (BioERG) and the Department of Chemical Engineering, Cape Peninsula University of Technology, Bellville campus, South Africa. wastewater using various organic and easily utilisable carbon sources with low operational cost [12]. SRB are well known for heavy metal precipitation as metal sulphides under anaerobic conditions. This process reduces sulphate to sulphide, and raise the $\mathrm{pH}$ of the AMD being remediated.

Bioreactor configuration is one of the factors that influence the performance of the SRB in wastewater treatment. Several bioreactor designs such as batch reactors, continuously stirred tank reactors, anaerobic filters, gas-lift reactors, fluidised bed reactors and membrane reactors, among others have been developed and harnessed successfully for biological sulphate reduction [13]. The performance of the bioreactor can be appraised either through an empirical approach which requires several experiments or by simulation. The latter involves the use of mathematical model simulation software for experimental designs in order to improve the reliability of the experimental results. Modelling approach has the advantage of being able to predict both current and future events while reducing the number of experiments to be completed.

AQUASIM is a tool for the identification and simulation of aquatic systems. AQUASIM program can be used to simulate systems such as mixed reactors, biofilm reactors, advective-diffusive reactors, saturated soil column, river system, lake system and sediment system [14]. Therefore, the presented work attempts to model substrate utilisation and SRB proliferation in AMD during sulphate reduction using AQUASIM v2.1.

\section{METHODOLOGY}

\section{A. Sample collection, isolation and growth media}

Samples of acid mine drainage collected were used to explore the presence of sulphate reducing bacteria in a Postgate isolation media as described in Akinpelu et al [15].

\section{B. Batch experiment}

Experiments were carried out in a $1 \mathrm{~L}$ continuously stirred tank reactors (CSTRs) under anaerobic conditions. The bioreactor operated for 21 days at $35^{\circ} \mathrm{C}$ and $\mathrm{pH}$ of 7 contained $800 \mathrm{~mL}$ Postgate isolation media inoculated with $100 \mathrm{~mL}$ of inoculum. Samples (70\% v/v) were drawn weekly and replaced with fresh Postgate isolation medium. To minimize methanogesis, sodium bromoethane sulphonate $(3.2 \mathrm{~g} / \mathrm{L})$ was added to the bioreactor during enrichment (21 days). Subsequently, acid mine drainage $(100 \mathrm{~mL})$ was added to the bioreactor, operated in a continuous mode for 7 days and 
sampled at predetermined intervals. The microbial growth was observed in a GENESYS ${ }^{\mathrm{TM}}$ 10S UV-Vis spectrophotometer (Thermo Fisher Scientific ${ }^{\mathrm{TM}}$, Waltham, MA, USA) based on optical density at a wavelength of $600 \mathrm{~nm}$. Control experiments were not inoculated with SRB. All measurements were in triplicate.

\section{Model description}

Mathematical models are essential tools for the interpretation and optimisation of biological processes. The Monod model is commonly used to describe the kinetics of microbial metabolism due to its mathematical simplicity. This model has been used for description of both methanogenesis and sulphate reduction in a CSTR under anaerobic conditions [16]. The model was able to predict the steady-state and batch spike experimental data considerably well without considering $\mathrm{pH}$ modulation and sulphide inhibition. The microbial specific growth rate $(\mu)$ is related to the concentration of the limiting substrate $(S)$ as shown in Eq. (1):

$$
\mu=\frac{r \max S}{K+S}
$$

where rmax is the maximum specific growth rate of the biomass and $K$ is the Monod saturation constant.

In addition, Kalyuzhnyi et al [17] also modelled the growth of sulphate reducing bacteria (SRB) using Monod kinetics, albeit, taking into account $\mathrm{pH}$ fluctuation and undissociated $\mathrm{H}_{2} \mathrm{~S}$ inhibition. The undissociated $\mathrm{H}_{2} \mathrm{~S}$ was expressed as a first order for the SRB and the specific growth rate formulated as in Eq. (2):

$$
\mu=\operatorname{rmax} \frac{[S] F(p H)}{K_{s}+S}\left[1-\left(\frac{\left[H_{2} S\right]}{K_{l}}\right)\right]\left(\frac{\left[S_{4}^{2-}\right]}{K_{n}+\left[S O_{4}^{2-}\right]}\right)
$$

Where $F(\mathrm{pH})$ is the $\mathrm{pH}$ inhibition function, $S$ is the organic substrate concentration, $K_{I}$ is the inhibition constant of undissociated hydrogen sulphide, $K_{n}$ is the Monod saturation constant for sulphate, and $K_{s}$ is the Monod saturation constant for the organic substrate.

Furthermore, previous studies have shown that when microorganisms are grown in an environment with more than a substrate, the kinetics of the microbial growth can either be interactive or non-interactive. When the microbial specific growth rate is limited by only one substrate, the model is considered non-interactive. Meanwhile, in the interactive model, many substrates affect the overall microbial specific growth rate, and one substrate can also affect the uptake of other essential substrates. When the uptake of one substrate does not affect the uptake of the other substrate, a model can be established by a product of individual substrate utilisation as in Eq. (3) [18]:

$$
\mu=\operatorname{rmax} \frac{S_{1}}{K_{1}+S_{1}} \frac{S_{2}}{K_{2}+S_{2}}
$$

Where $S_{1}$ and $S_{2}$ are concentrations of substrates 1 and 2, respectively, with $K_{1}$ and $K_{2}$ being saturation constants of substrates 1 and 2 , respectively.

\section{Biomass growth stoichiometry}

For lactate degrading SRB, biomass yield and specific growth rate parameters can be estimated from the thermodynamics of microbial growth based on catabolic and anabolic stoichiometric reactions [19, 20]. During microbial growth, a portion of the substrate is used up during catabolism where hydrogen sulphide is precipitated as in Eq. (4) [21]:

$$
\mathrm{C}_{3} \mathrm{H}_{6} \mathrm{O}_{3(\mathrm{aq})}+\frac{1}{2} \mathrm{H}_{2} \mathrm{SO}_{4(\text { aq })} \rightarrow \mathrm{C}_{2} \mathrm{H}_{4} \mathrm{O}_{2(\mathrm{aq})}+\frac{1}{2} \mathrm{H}_{2} \mathrm{~S}_{(\mathrm{g})}+\mathrm{CO}_{2(\mathrm{aq})}+\mathrm{H}_{2} \mathrm{O}_{(\mathrm{l})}
$$

For the anabolic process, assuming molecular composition of SRB biomass as $\mathrm{C}_{5} \mathrm{H}_{7} \mathrm{O}_{2} \mathrm{~N}$ [22], the anabolic reaction can be expressed as Eq. (5):

$$
\frac{5}{3} \mathrm{C}_{3} \mathrm{H}_{6} \mathrm{O}_{3(\mathrm{aq})}+\mathrm{NH}_{3(\mathrm{aq})} \rightarrow \mathrm{C}_{5} \mathrm{H}_{7} \mathrm{O}_{2} \mathrm{~N}+3 \mathrm{H}_{2} \mathrm{O}_{(\mathrm{l})}
$$

The overall stoichiometric description of SRB growth when lactate is used as a carbon source is a combination of equations (4) and (5) as highlighted in Eq. (6):

$$
\begin{aligned}
& \frac{8}{3} \mathrm{C}_{3} \mathrm{H}_{6} \mathrm{O}_{3(\mathrm{aq})}+\frac{1}{2} \mathrm{H}_{2} \mathrm{SO}_{4(\text { aq })}+\mathrm{NH}_{3(\text { aq })} \rightarrow \\
& \mathrm{C}_{5} \mathrm{H}_{7} \mathrm{O}_{2} \mathrm{~N}+\mathrm{C}_{2} \mathrm{H}_{4} \mathrm{O}_{2(\text { aq })}+\frac{1}{2} \mathrm{H}_{2} \mathrm{~S}_{(\mathrm{g})}+\mathrm{CO}_{2(\text { aq })}+4 \mathrm{H}_{2} \mathrm{O}_{(\mathrm{l})}
\end{aligned}
$$

\section{E. Model processes and components}

The modelling and simulation were done in the AQUASIM v2.1 tool [14]. The experimental results of rmax and $K$ were 0.30 per day and $1.7 \mathrm{mg} / \mathrm{l}$, respectively, which are closely related to those reported by Gupta et al [16] for biological sulphate reduction using the Monod's kinetic model. As a result, the Monod's kinetic model was used with the following input components:

- Lactate and biomass are state variables;

- Kinetic constants; rmax and $K$ were 0.36 per day and $0.84 \mathrm{mg} / \mathrm{l}$, respectively from Gupta et al [16];

- Stoichiometric matrix is as defined in Eq. (6);

- Experimental values of lactate utilisation and biomass formation were real list variables;

- Initial lactate concentration (C_Aini) was $10 \mathrm{mg} / \mathrm{l}$;

- A mixed reactor compartment with a constant volume of $1 \mathrm{~L}$ was used;

- The system was simulated stepwise with 0.1 intervals and 70 steps;

- Sensitivity analysis was done using the absolute relative sensitivity function for substrate and biomass concentration with rmax, $K$ and initial lactate concentration being constant;

- Parameter estimation was done using the secant method with a maximum of 100 iterations; and

- Inhibitory effects of heavy metals and sulphite, 
including $\mathrm{pH}$ fluctuations were considered to be minimal.

\section{RESULTS AND DisCUSSION}

\section{A. Substrate utilization and biomass formation}

The model was calibrated using data from a continuous reactor mode operation of 7 days. During this stage, the CSTR was fed with $100 \mathrm{~mL}$ AMD containing $8080 \mathrm{mg} \mathrm{SO}_{4}{ }^{2-} / \mathrm{L}$ which was gradually reduced to $1195 \mathrm{mg} \mathrm{SO}_{4}{ }^{2-} / \mathrm{L}$ at the end of the $7^{\text {th }}$ day of reactor operation. The initial values of constant variables were analogous to those obtained in Guptal et al [16] for substrate (lactate) consumption and biomass formation over time during sulphate reduction. The profile in Fig. 1 shows the exponential decrease in substrate concentration while there was an exponential increase in biomass formed over time.

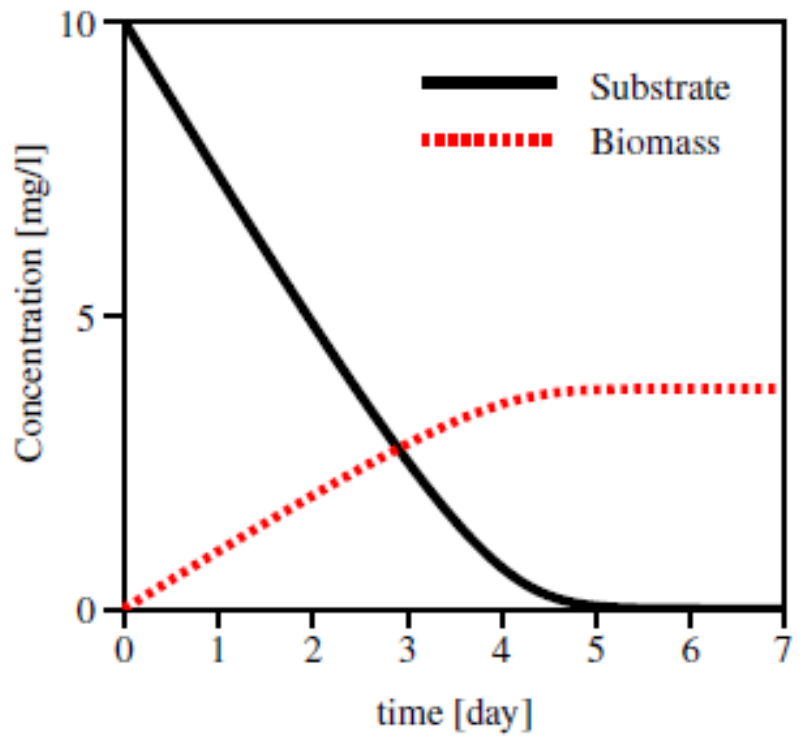

Fig. 1. Substrate uptake and biomass formation profile

\section{B. Model simulation and parameter estimation}

The simulation of experimental values with the model in Fig. $2 \mathrm{~A}$ shows that the initial parameter values were undescriptive of both substrate utilisation and biomass formation. Although, Guptal et al [16] reported sufficient correlation between experimental data and model prediction, albeit, their simulation was for a system not as rich in heavy metal as in the AMD used in this study. Similarly, the high sulphate concentration (8080 $\mathrm{mg} \mathrm{SO}_{4}{ }^{2-} / \mathrm{L}$ ) in the AMD sample would have contributed to the disparity unlike $4.16 \mathrm{mg} / \mathrm{L}$ in Guptal et al [16] report. Parameter estimation of the initial parameters: rmax and $K$ were estimated using secant method minimised the standard deviations, confirming the suitability of the stoichiometric matrix as well as the kinetic parameters used see - Fig. 2B. Iterations $(n=12)$ were required to reach convergence of the parameters estimated. The value of rmax increased from 0.36 to 0.59 per day and that of $K$ increased from 0.84 to $8.4 \mathrm{mg} / \mathrm{L}$. The deviation between the model and experimental data decreased from 684.5 to 44.13 . The estimated correlation matrix showed a large correlation between parameters for substrate consumption whereas there was a lower correlation between the parameters for biomass formed. The variation may be explained by the sensitivity functions of the state variables with respect to constant parameters used $(\operatorname{rmax}, K$, ).

A

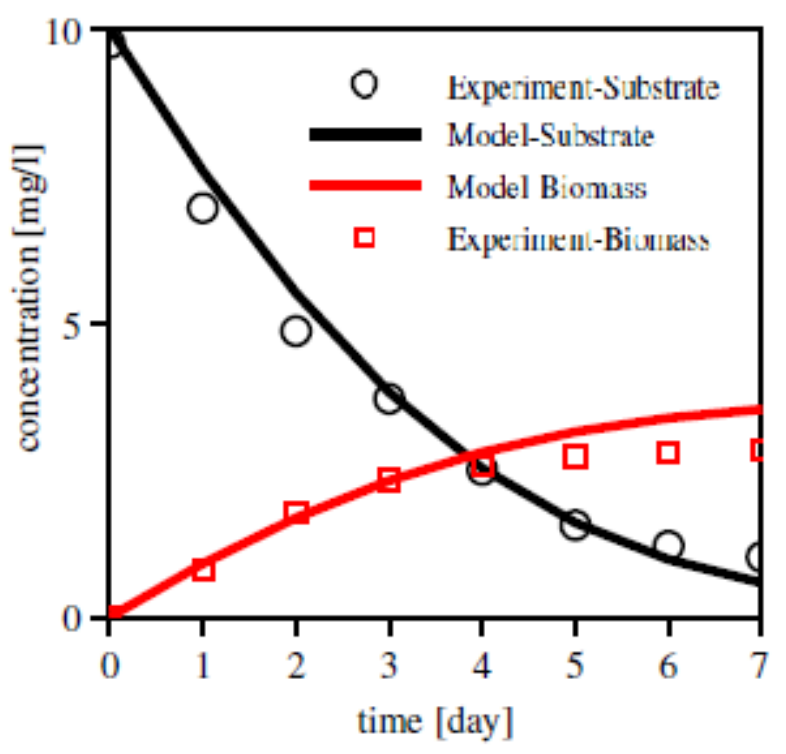

B

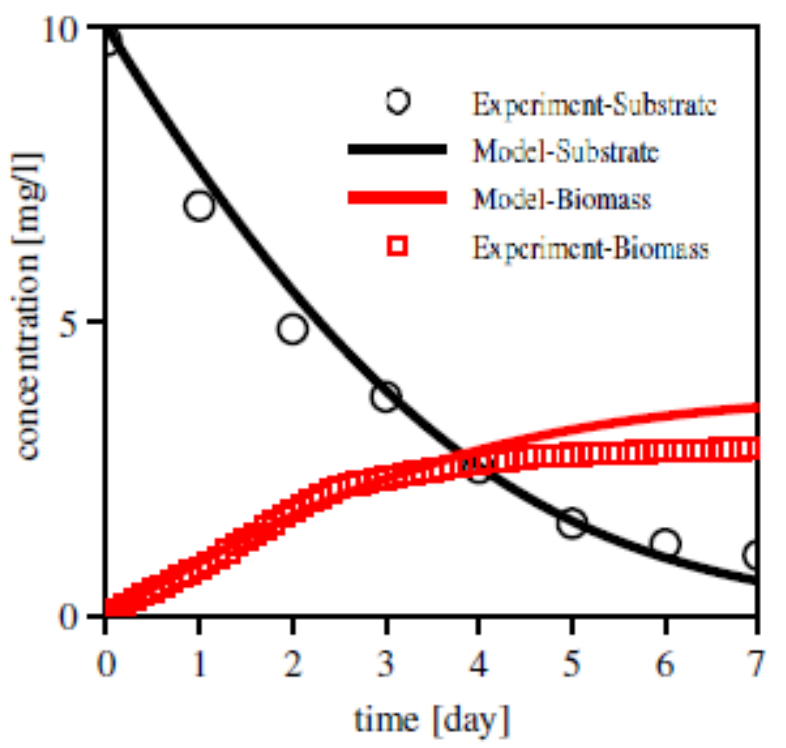

Fig. 2. Comparison of model simulation and experimental data before (A) and after (B) parameter estimation

\section{Sensitivity analysis}

The absolute relative sensitivity functions were performed based on two scenarios. First, the initial substrate concentration was assumed to be constant - Figure 3. The sensitivity of substrate to $C_{-}$Aini has its maximum at time of zero, and decreases exponentially - Figure 3A. Meanwhile, with respect to rmax, the sensitivity of substrate increases from zero to a maximum and then decreases again to zero. An indication that the substrate concentration decreases with increasing rmax, 
which is peculiar behaviour of the absolute value of the sensitivity function [23]. The sensitivity of substrate with respect to $K$ is similar in shape to changes in rmax with different sign and magnitude, which make the parameters ( $\max$ and $K$ ) non-identifiable from measured substrate data. The sensitivity of biomass has its minimum at time of zero for all the three parameters - Figure 3B. For C_Aini, the biomass sensitivity increases exponentially, while for rmax and $K$, sensitivity functions are alike in shape but differs in sign and magnitude, any change induced by one parameter can be compensated by an appropriate change in the other parameter. Only the parameter C_Aini is identifiable from measured data of both substrate and biomass.

A

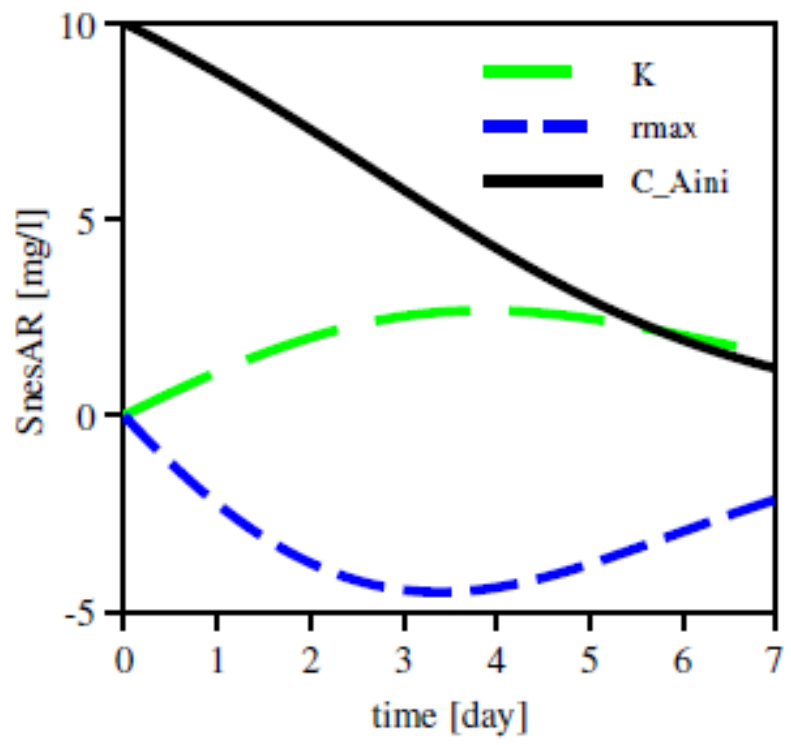

B

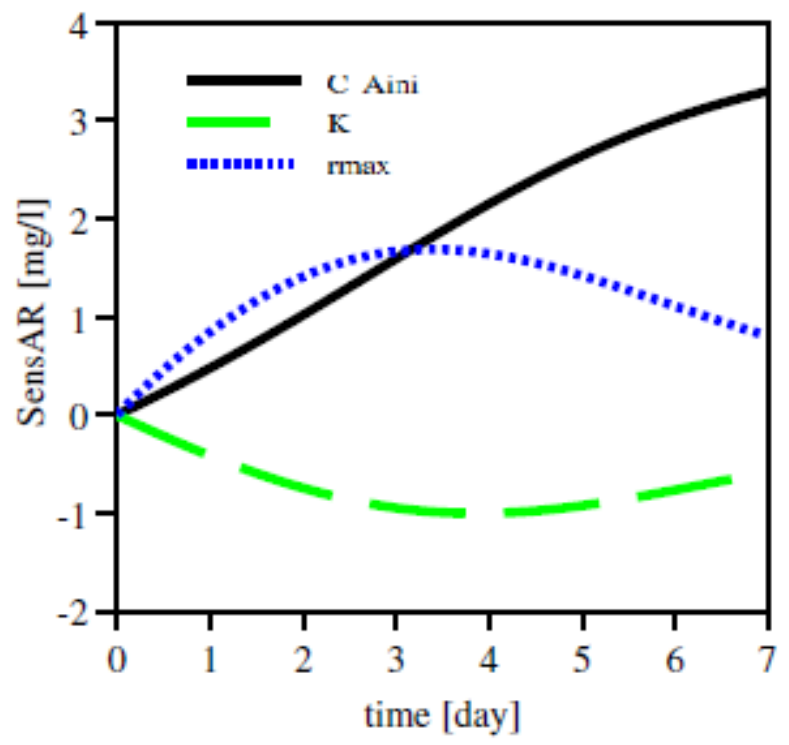

Fig. 3 Sensitive function for substrate (A) and Biomass (B) at constant initial substrate condition

Secondly, taking initial substrate conditions in the reactor compartment as real list experimental values - Figure 4 . The plot shows that both substrate and biomass are insensitive to initial substrate concentration ( $C_{-}$Aini). The dependence of substrate and biomass on other parameters ( $\max , K)$ are different. The sensitivity functions of both substrate and biomass with respect to rmax and $K$ are similar in shape with different sign and magnitude. This implies that any change in rmax can be compensated by appropriate change in $K$, which makes the two parameters non-identifiable from measured data of substrate and biomass. This is because the concentration of substrate and biomass are not larger than the half saturation constant $K$.

A

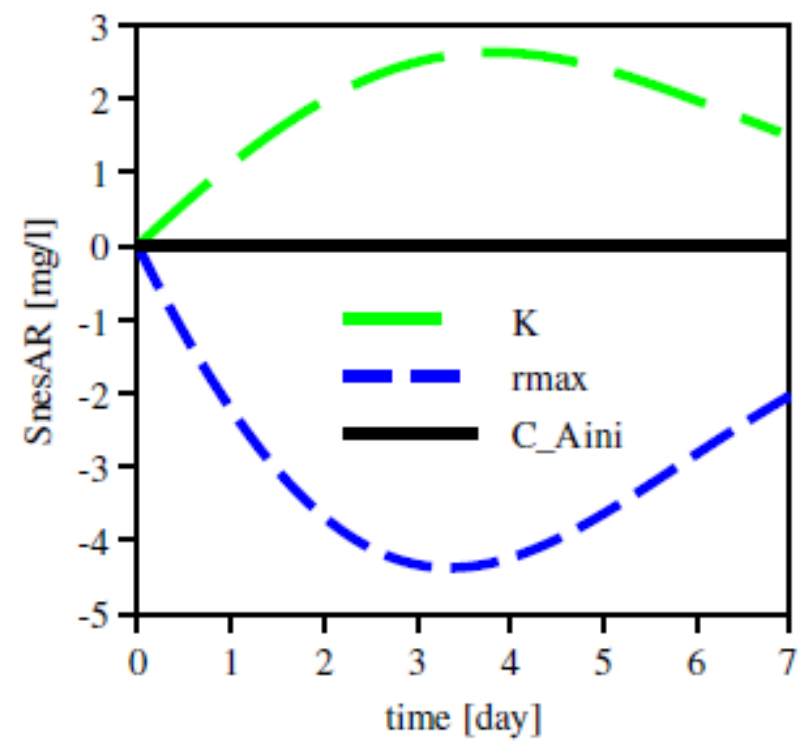

B

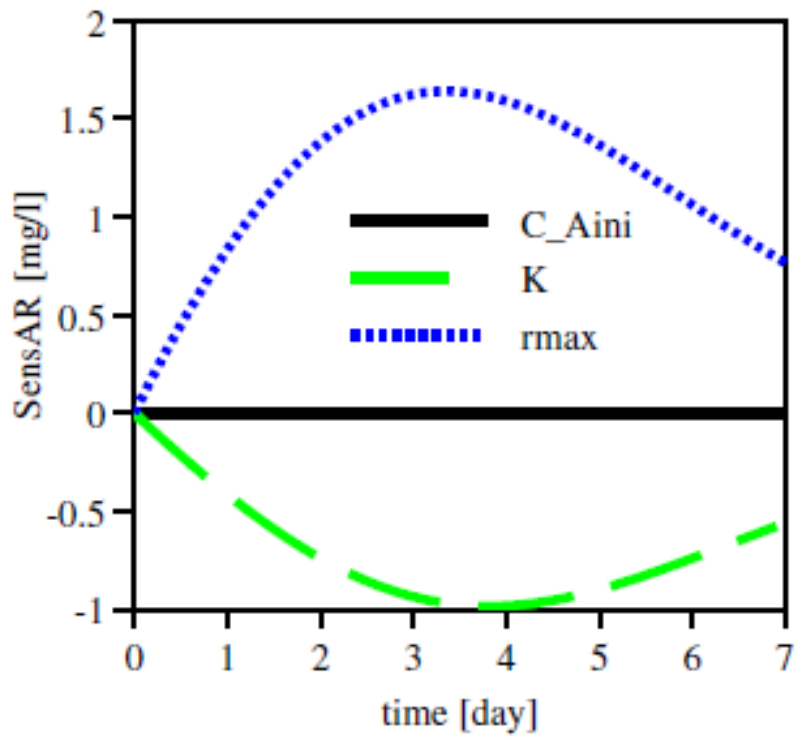

Fig. 4 Sensitive functions for substrate (A) and Biomass (B) at real list experimental values as initial conditions

\section{CONCLUSION}

The simulated model was a better fit for substrate utilisation model while it was rudimentary in describing biomass formation. This can be attributed to effect of inhibitors and 
associated heavy metals the AMD used which were not considered for the model. Modification of kinetic parameters in the model increased the correlation between the model and the experimental values. The absolute relative sensitivity function indicated that the saturation constant and the maximum biomass growth were the most significant parameters in the model. Therefore, this study forms the basis for further model development in biological remediation of AMD. In addition, modification of kinetic expressions to incorporate the role of inhibitors and heavy metals must be considered.

\section{ACKNOWLEDGMENT}

E.A. Akinpelu appreciate the Netherlands Government for the award of OKP Fellowship for training on Modelling Wastewater Treatment Processes and Plants. The NRF sponsor for the Fellowship is also acknowledged.

\section{REFERENCES}

[1] Z. Liu, L. Li, Z. Li, and X. Tian, "Removal of sulfate and heavy metals by sulfate-reducing bacteria in an expanded granular sludge bed reactor," Environmental Technology, vol. 39, no. 14, pp. 1814-1822, July, 2018. https://doi.org/10.1080/09593330.2017.1340347

[2] Elvis Fosso-Kankeu. 2019. Nano and Bio-based Technologies for wastewater treatment: Prediction and Control Tools for the dispersion of Pollutants in the Environment. Wiley Scrivener. ISBN: 978-1-119-57709-6. Pp 301-336.

[3] Elvis Fosso-Kankeu. 2019. New Horizons in Wastewaters Management: Emerging Monitoring and Remediation Strategies. Nova Science Publishers. ISBN: 978-1-53615-659-1.

[4] IG Erdogan, E Fosso-Kankeu, SKO Ntwampe, FB Waanders, N Hoth and A Rand. 2019. Acid rock drainage prediction of metalliferous soils from O'kiep, Namaqualand, South Africa: A humidity cell test assessment. IMWA 2019 Conference "Mine Water - Technological and Ecological Challenges". 15-19 July 2019, Perm, Russia. Elena Khayrulina and Christian Wolkersdorfer. ISBN: 978-5-91252-145-4. Pp 613-618.

[5] E. Fosso-Kankeu, A. Manyatshe, F. Waanders, Mobility potential of metals in acid mine drainage occurring in the Highveld area of Mpumalanga Province in South Africa: Implication of sediments and efflorescent crusts. International Biodeterioration and Biodegradation. Vol. 119, pp. 661-670, 2017. https://doi.org/10.1016/j.ibiod.2016.09.018

[6] E. Fosso-Kankeu, 2018. Synthesized af-PFCl and GG-g-P(AN)/TEOS hydrogel composite used in hybridized technique applied for AMD treatment. Journal of Physics and Chemistry of the Earth. 2018. https://doi.org/10.1016/j.pce.2018.02.015

[7] E. Fosso-Kankeu, A. Manyatshe, A. Munyai, F. Waanders, AMD formation and dispersion of inorganic pollutants along the main stream in a mining area. In: Drebenstedt, C. \& Paul, M.: IMWA 2016 - Mining Meets Water - Conflicts and Solutions. - p. 391 - 397; Freiberg/Germany (TU Bergakademie Freiberg). 2016.

[8] E. Fosso-Kankeu, Investigation of the oxidation rate of sediments from AMD using humidity cell test. International Conference on Advances in Science, Engineering, Technology and Natural Resources (ICASETNR-16) Nov. 24-25, 2016, Parys - South Africa. ISBN: 978-93-84468-79-8. 2016.

[9] H. Greben, J. Maree, Y. Singmin, and S. Mnqanqeni, "Biological sulphate removal from acid mine effluent using ethanol as carbon and energy source," Water Science and Technology, vol. 42, no. 3-4, pp. $339-344,2000$ https://doi.org/10.2166/wst.2000.0400

[10] J. Richa, K. Sonu, A. Himanshu, Y. A. Kumar, K. Santosh, and M. Abhilasha, "Heavy Metal Bio-accumulating Microbial Isolates for Remediation of Metal Contaminants from Industrial Effluents," International Journal of Microbiology Research, vol. 9, no. 1, pp. 837-841, 2017.

[11] J. Cassidy, H. J. Lubberding, G. Esposito, K. J. Keesman, and P. N. Lens, "Automated biological sulphate reduction: a review on mathematical models, monitoring and bioprocess control," FEMS microbiology reviews, vol. 39, no. 6, pp. 823-853, 2015

https://doi.org/10.1093/femsre/fuv033

[12] W. Liamleam, and A. P. Annachhatre, "Electron donors for biological sulfate reduction," Biotechnology Advances, vol. 25, no. 5, pp. 452-463, 2007/09/01/, 2007. https://doi.org/10.1016/j.biotechadv.2007.05.002

[13] A. H. Kaksonen, and J. A. Puhakka, "Sulfate Reduction Based Bioprocesses for the Treatment of Acid Mine Drainage and the Recovery of Metals," Engineering in Life Sciences, vol. 7, no. 6, pp. 541-564, 2007. https://doi.org/10.1002/elsc.200720216

[14] P. Reichert, "Aquasim 2.0-user manual," Swiss Federal Institute for Environmental Science and Technology. Dubendorf, Switzerland, 1998.

[15] E. A. Akinpelu, E. Fosso-Kankeu, F. Waanders, and K. O. Ntwampe, "Biological reduction of COD and sulphate by SRB in anaerobic moving bed biofilm reactor under high metal loading conditions." pp. 126-129, 2018.

[16] A. Gupta, J. R. V. Flora, G. D. Sayles, and M. T. Suidan, "Methanogenesis and sulfate reduction in chemostats-II. Model development and verification," Water Research, vol. 28, no. 4, pp. 795-803, 1994/04/01/, 1994. https://doi.org/10.1016/0043-1354(94)90086-8

[17] S. Kalyuzhnyi, V. Fedorovich, P. Lens, L. Hulshoff Pol, and G. Lettinga, "Mathematical modelling as a tool to study population dynamics between sulfate reducing and methanogenic bacteria," Biodegradation, vol. 9, no. 3, pp. 187-199, May 01, 1998. https://doi.org/10.1023/A:1008339018423

[18] R. D. Megee Iii, J. F. Drake, A. G. Fredrickson, and H. M. Tsuchiya, "Studies in intermicrobial symbiosis. Saccharomyces cerevisiae and Lactobacillus casei," Canadian Journal of Microbiology, vol. 18, no. 11, pp. 1733-1742, 1972/11/01, 1972. https://doi.org/10.1139/m72-269

[19] E. A. Akinpelu, E. Fosso-Kankeu, S. K. O. Ntwampe, and F. Waanders, "Stoichiometric and thermodynamic analysis: Implications in bioremediation," New Horizons in Wastewaters Management, E. Fosso-Kankeu, ed., pp. 151-171, New York: Nova Science Publishers, 2019.

[20] E. H. Battley, "The thermodynamics of microbial growth," Handbook of thermal analysis and calorimetry, From macromolecules to man R. B. Kemp, ed., pp. 219-266, Amsterdam: Elsevier, 1999. https://doi.org/10.1016/S1573-4374(99)80008-9

[21] S. Okabe, and W. G. Characklis, "Effects of temperature and phosphorous concentration on microbial sulfate reduction by Desulfovibrio desulfuricans," Biotechnology and Bioengineering, vol. 39, no. 10, pp. 1031-1042, 1992. https://doi.org/10.1002/bit.260391007

[22] S. W. Sötemann, P. van Rensburg, N. E. Ristow, M. C. Wentzel, R. E. Loewenthal, and G. A. Ekama, "Integrated chemical, physical and biological processes modelling of anaerobic digestion of sewage sludge," Water Science and Technology, vol. 54, no. 5, pp. 109-117, 2006. https://doi.org/10.2166/wst.2006.553

[23] P. Reichert, "Design techniques of a computer program for the identification of processes and the simulation of water quality in aquatic systems," Environmental Software, vol. 10, no. 3, pp. 199-210, 1995/01/01/, 1995.

https://doi.org/10.1016/0266-9838(95)00010-I 